\title{
Immobilised nickel(II), dioxomolybdenum(VI) and dioxouranium(VI) complexes on polystyrene resin
}

\author{
Amit Kumar ${ }^{1}$, Praveen Kumar Gupta ${ }^{2}$, Dinesh Kumar ${ }^{3}$ and Sunil Kumar ${ }^{2}$ \\ ${ }^{1}$ Department of Chemistry, Indira Gandhi National College, Ladwa, Kurukshetra-136118 \\ (Haryana) India \\ ${ }^{2}$ Department of Chemistry, Maharishi Markandeshwar (Deemed to be University), Mullana, \\ Ambala-133207 (Haryana) India \\ ${ }^{3}$ Deptt. of Chemistry, National Institute of Technology, Kurukshetra136119 (Haryana) India \\ ${ }^{2}$ Corresponding author: parveen.gupta@mmumullana.org
}

\begin{abstract}
A new polystyrene supported mixed Schiff bases( $\left.\mathrm{PSCH}_{2}-\mathrm{LH}_{2}\right)$ and their coordination compounds with nickel(II), dioxomolybdenum(VI) and dioxouranium(VI) have been synthesized. PSCH ${ }_{2}-\mathrm{LH}_{2}$ has been synthesized by the reaction of chloromethylated polystyrene crosslinked with divinylbenzene(PSCH $2-C l)$ and the Schiff bases( $\left.\mathrm{LH}_{2} \mathrm{P}_{2}\right)$ derived from 3formylsalicylic acid, ethylenediamine or propylenediamine and acetylacetone. The polystyrene supported coordination compounds are of the types: $\mathrm{PSCH}_{2}-$ $L M\left(\right.$ wh ere $\left.\mathrm{M}=\mathrm{Ni}, \mathrm{MoO}_{2}, \mathrm{UO}_{2}\right)$. They have been synthesized by the reaction of $\mathrm{PSCH}_{2}-\mathrm{LH}_{2}$ and the metal salt/metal coordination compounds in DMF. The coordination compounds have been char acterized on the basis of elemental analyses, IR, reflectance and magnetic susceptibility measurements. The shifts of the $v(C=N)$ (azomethine), $v(C-O)$ (phenolic) and $v(C-O)$ (enolic) stretches indicate the ONNO donor behaviour of $\mathrm{PSCH}_{2}-\mathrm{LH}_{2}$. The polystyrene supported $\mathrm{Ni}(\mathrm{II})$ compound is square planar; $\mathrm{MoO}_{2}$ (VI) and $\mathrm{UO}_{2}$ (VI) compounds are octahedral and $\operatorname{Zr}(I V)$ compounds are pentagonal bipyramidal. The compounds, $\mathrm{PSCH}_{2}-\mathrm{LM}\left(\right.$ wh ere $\mathrm{M}=\mathrm{Ni}, \mathrm{MoO}_{2}$ and $\left.\mathrm{UO}_{2}\right)$ are diamagnetic.
\end{abstract}

Keywords: Chloromethylated Polystyrene, coordination complex, mixed Schiff base, paramagnetic diamagnetic

\section{INTRODUCTION}

Immobilization of transition metal ions on the polymer support provides an easy route for the syntheses of immobilized coordination compounds. The chelating resins have numerous applications in various fields like catalysts[1-4][e.g. Fe(III) anchored to polystyrene supported Schiff base is effective in the epoxidation of cis-cyclooctene and styrene in presence of tertbutylhydroperoxide], separation of metal ions[5-8][e.g. chelating polystyrene divinylbenzene based resin containing quinaldinic acid amide group has been 
used for the quantitative separation of Pd(II) and Pt(IV)]; chromatography[911][e.g. immobilized Pd(II) on a phosphine sulphide derivated polystyrene as chromatographic material for the selective adsorption of amino acids] etc. Since the stability of coordination compounds increases with the increase in the number of chelate rings, it is of interest to immobilize multidentate ligands into the polymer matrix. The syntheses of crosslinked polystyrene bound tetradentate ligands such as iminobis (propylenesalicylideneimine)[12,13], tetrathiol[14], 2,2' -[diimino-1,2-ethane-diylbis(1,2-ethanediylnitrilomethylidyne)]di-phenol[15],

phthalocyanine[16]. Tetraazomacrocyclics[17,18], N, N'-ethylenemono(3carboxysalicylidene- imine)mono(salicylideneimine)[19] etc. have been reported. In this chapter, anchoring of mixed Schiff bases, $\mathrm{PSCH}_{2}-\mathrm{LH}_{2}$ (I) derived from 3formylsalicylic acid, propylenediamine and acetylacetone to polystyrene matrix is described. The polystyrenes supported mixed Schiff bases have been used to synthesize polystyrene supported coordination compounds of nickel(II), dioxomolybdenum(VI) and dioxouranium(VI).<smiles></smiles>

I

\section{EXPERIMENTAL}

\subsection{Materials}

Chloromethylated polystyrene cross-linked with $1 \%$ divinylbenzene beads(PS-Cl) (having $1.17 \mathrm{mmol}$ of $\mathrm{Cl}$ per gram) [Sigma Chemical Co. (USA)], nickel acetate tetrahydrate, dioxouranium(VI) acetate tetrahydrate [BDH], Acetylacetone, propylenediamine [Sarabhai M. Chemicals], were used for the syntheses. Bis(acetylacetonato)dioxomolybdenum(VI) was synthesised by the procedure reported by G. J. Chen, J. W. McDonald and W. E. Newton,3-formyl salicylic acid was synthesised by the procedure reported by J.C. Duff. All solvents used were dried over molecular sieves.

\subsection{Analyses and Physical Meausrements}

The metal contents, IR, reflectance spectral studies of the polystyreneanchored coordination compounds were carried out as repoted earlier in our publications[5]. 


\subsection{Syntheses of Schiff bases, $\mathrm{LH}_{2}(\mathrm{I})$}

An ethanolic solution(30 ml) of 3-formylsalicylic acid(1.66 g, $10 \mathrm{mmol})$ was mixed with an ethanolic solution $(15 \mathrm{ml})$ of acetylacetone $(1.0 \mathrm{~g}, 10 \mathrm{mmol})$. The mixture was kept in an ice bath for $1 / 2 \mathrm{~h}$. An ethanolic solution of propylenediamine $(0.74 \mathrm{~g}, 10 \mathrm{mmol})$ was added slowly to the above mixture with constant stirring. The mixture was heated under reflux for $45 \mathrm{~min}$ and was cooled in an ice bath. The yellow precipitates separated were suction filtered, washed several times with ethanol and finally dried in vacuo at room temperature. Yield $=80 \%$.

\subsection{Syntheses of Polystyrene-anchored Schiff bases, $\mathrm{PSCH}_{2}-\mathrm{LH}_{2}(\mathrm{I})$}

Chloromethylated polystyrene(1.0 g) was suspended in $\operatorname{DMF}(20 \mathrm{ml})$ for 45 min. A DMF solution $(40 \mathrm{ml})$ of $\mathrm{LH}_{2}(0.86 \mathrm{~g}, 2.82 \mathrm{mmol})$ was added to the above suspension. The mixture was heated under reflux for $8 \mathrm{~h}$, while stirring magnetically in presence of ethyl acetate $(100 \mathrm{ml})$ and triethylamine(2 ml). The mixture was cooled to room temperature and the yellow coloured products obtained were suction filtered, washed thoroughly with DMF, ethyl acetate, ethanol, methanol and petroleum ether and then were dried in vacuo at room temperature.

\subsection{Method of the syntheses of polystyrene-anchored $\mathrm{Ni}(\mathrm{II})$, and $\mathrm{UO}_{2}$ (VI) coordination compounds}

Polystyrene-anchored Schiff base(I )(0.5 g) was suspended in DMF(25 ml) for $1 \mathrm{~h}$. To this suspension, a DMF solution(30-50 ml) of the appropriate metal acetate $(0.94 \mathrm{mmol})$ was added. The mixture was heated under reflux for $8 \mathrm{~h}$, while stirring magnetically. The products were cooled to room temperature and then suction filtered, washed several times with DMF, ethanol, methanol and acetone. The compounds were dried as mentioned above.

\subsection{Syntheses of $\mathrm{PSCH}_{2}-\mathrm{LMoO}_{2}$}

Polystyrene-anchored Schiff base, I (0.5 g, $0.47 \mathrm{mmol})$ was suspended in $\operatorname{DMF}(25 \mathrm{ml})$ for 1 h. A DMF solution $(30 \mathrm{ml})$ of bis(acetylacetonato)dioxomolybdenum( $0.31 \mathrm{~g}, 0.94 \mathrm{mmol})$ was added to the above suspension. The mixture was heated under refluxed for $5 \mathrm{~h}$, while stirring magnetically and then cooled to room temperature. The compounds obtained were suction filtered, washed with DMF, ethanol, methanol and acetone and dried as mentioned above. 


\section{RESULTS AND DISCUSSION}

The polystyrene-anchored Schiff bases(I) were synthesized by reacting chloromethylated polystyrene( $\left.\mathrm{PSCH}_{2}-\mathrm{Cl}\right)$ and the mixed Schiff base $\left(\mathrm{LH}_{2}\right)$ in $1: 3$ ratio respectively in DMF. The reaction was carried out for $8 \mathrm{~h}$ and the ratio of $\mathrm{PSCH}_{2}-\mathrm{Cl}$ : Schiff bases being 1:3. If the time was less than $8 \mathrm{~h}$ and also the ratio being $1:<3$, the polystyrene-anchored Schiff bases always contained some unreacted $\mathrm{CH}_{2} \mathrm{Cl}$ group. The polystyrene-anchored Schiff bases are insoluble in aqueous and non-aqueous solvents. However, they undergo considerable swelling in DMF. In the present study, DMF was chosen as the solvent due to its high dielectric constant and its ability to dissolve large number of metal salt/metal complexes. The chloromethylated polystyrene crosslinked with only $1 \%$ divinylbenzene was selected because a higher crosslinking affects the metal binding power of $\mathbf{I}$. The colour of $\mathrm{PSCH}_{2}-\mathrm{Cl}$ is white and that of $\mathbf{I}$ is pale yellow. As the reaction progresses, the white colour of $\mathrm{PSCH}_{2}-\mathrm{Cl}$ changes to pale yellow. The colour of polystyrene-anchored Schiff bases remain unchanged even after thorough washings with DMF, ethyl acetate, ethanol and methanol.

The syntheses of polystyrene anchored Schiff bases( $\left.\mathrm{PSCH}_{2}-\mathrm{LH}_{2}\right)$ (I) and their coordination compounds are shown as per Scheme 1.

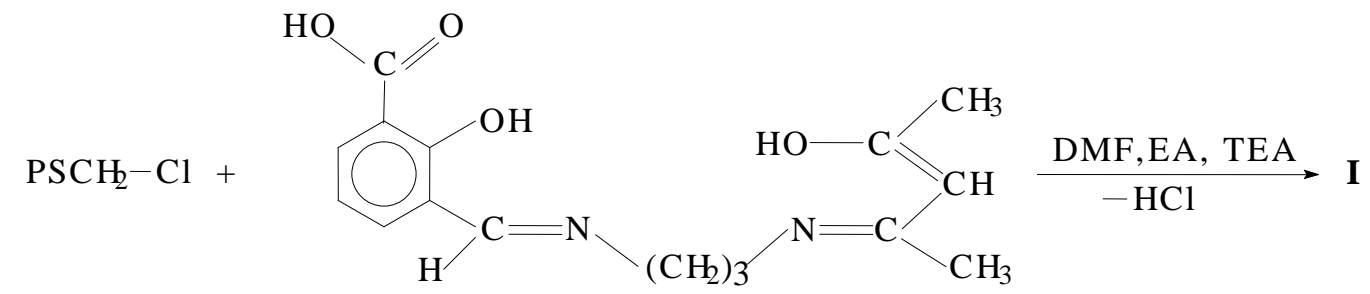

Scheme 1. EA = ethyl acetate and TEA = triethylamine

$$
\begin{array}{r}
\mathrm{PSCH}_{2}-\mathrm{LH}_{2}+\mathrm{M}\left(\mathrm{CH}_{3} \mathrm{COO}\right)_{2} \underset{\text { reflux }}{\stackrel{\text { DMF }}{\longrightarrow}} \mathrm{PSCH}_{2}-\mathrm{LM}+2 \mathrm{CH}_{3} \mathrm{COOH} \\
{\left[\mathrm{M}=\mathrm{Ni}(\mathrm{II}) \text { and } \mathrm{UO}_{2}(\mathrm{VI})\right]} \\
\left.\mathrm{PSCH}_{2}-\mathrm{LH}_{2}+\mathrm{MoO}_{2} \text { (acac) }\right)_{2} \underset{\text { reflux }}{\stackrel{\mathrm{DMF}}{\longrightarrow}} \mathrm{PSCH}_{2}-\mathrm{LMoO}_{2}+\text { acacH }
\end{array}
$$

The syntheses of polystyrene-anchored coordination compounds were carried out in 1:2 molar ratio of polystyrene-anchored Schiff base to metal salt/metal complex. The colour of the polystyrene-anchored coordination compounds are yellow green, yellow or orange depending on the metal salts used. The colour of the polystyrene-anchored coordination compounds remains 
unchanged even after prolonged washings with DMF, ethanol, methanol and acetone. The polystyrene-anchored coordination compounds have 1:1 metal:ligand stoichiometry(Table 1). The percent reaction conversion of the polystyreneanchored coordination compound varies from 38.0-92.4(Table 1). There is no apparent correlation between percent reaction conversion and the size of the metal ion. The metal binding capacity of the resins is $0.26-0.66 \mathrm{mmol}$ of metal per $g$ of resin(Table 1). The metal ions can be easily stripped from the polystyrene-anchored coordination compounds by dilute acids.

Table1. Colour and Analytical Data of Polystyrene-Anchored Coordination Compounds

\begin{tabular}{|l|l|l|l|l|}
\hline $\begin{array}{l}\text { Polysty rene-anchored } \\
\text { Complexes }\end{array}$ & Colour & $\begin{array}{l}\text { Found(Cal } \\
\text { cd.) }(\mathbf{\%})\end{array}$ & $\begin{array}{l}\text { Metal-binding capacity } \\
(\times \mathbf{1 0}) \mathbf{( m m o l} / \mathbf{g} \text { of } \\
\text { resin) }\end{array}$ & $\begin{array}{l}\text { Percent } \\
\text { conversion }\end{array}$ \\
\hline $\mathrm{PSCH}_{2}-\mathrm{LNi}$ & $\begin{array}{l}\text { Yellowish } \\
\text { green }\end{array}$ & $\begin{array}{l}3.9 \\
(4.22)\end{array}$ & 66.4 & 92.4 \\
\hline $\mathrm{PSCH}_{2}-\mathrm{LMoO}_{2}$ & Yellow & $\begin{array}{l}2.5 \\
(6.58)\end{array}$ & 26.0 & 38.0 \\
\hline $\mathrm{PSCH}_{2}-\mathrm{LUO}_{2}$ & Orange & $\begin{array}{l}11.6 \\
(14.86)\end{array}$ & 48.7 & 78.1 \\
\hline
\end{tabular}

The infrared spectral bands of polystyrene-anchored Schiff base, $\mathrm{PSCH}_{2}-$ $\mathrm{LH}_{2}(\mathbf{I})$ and their coordination compounds are given in Table 2. 3Formylsalicylic acid exhibits $v(\mathrm{C}=\mathrm{O})(\mathrm{COOH})$ stretch[20] at $1660 \mathrm{~cm}^{-1}$. $\mathrm{LH}_{2}$ exhibit this band at $1670 \mathrm{~cm}^{-1}$ respectively. However, $\mathrm{PSCH}_{2}-\mathrm{LH}_{2}$ show two new bands at 1730 and $1640 \mathrm{~cm}^{-1}$ respectively. The former band is assigned to $v(\mathrm{C}=\mathrm{O})($ ester) and the latter band to $v(\mathrm{C}=\mathrm{N})$ (azomethine) and/or $v(\mathrm{C}=\mathrm{O})$ (ketone) of acetylacetone moiety. The positive shift of band from 1670 to $1730 \mathrm{~cm}^{-1}$ indicates the formation of covalent bond between $\mathrm{PSCH}_{2}-\mathrm{Cl}$ and $\mathrm{LH}_{2}$ [21]. The polystyrene-anchored coordination compounds also show the band at $\sim 1730 \mathrm{~cm}^{-1}$ which indicates the non-involvement of $v(C=O)$ (ester) of $\mathbf{I}$. However, the band at $1630 \mathrm{~cm}^{-1}$ in I shift to lower energy by $20-35 \mathrm{~cm}^{-1}$ in coordination compounds. The negative shift[22] of this band indicates the involvement of azomethine $\mathrm{N}$ atom towards coordination. $\mathrm{PSCH}_{2}-\mathrm{LH}_{2}$ occur in keto form as evident by the disappearance of $v(C=O)$ stretch of $\mathbf{I}$ upon coordination, also the coordination compounds show a new band at 1220-1230 $\mathrm{cm}^{-1}$ due to $v(\mathrm{C}-\mathrm{O})$ (enolic) stretch[23]. The presence of this band clearly indicates that $\mathbf{I}$ has undergone 
tautomerization upon complexation. The $v(\mathrm{C}-\mathrm{O})$ (phenolic) stretch of $\mathbf{I}$ occurring at $1530 \mathrm{~cm}^{-1}$ shifts to higher energy by $\leq 10 \mathrm{~cm}^{-1}$ in coordination compounds. The above positive shift indicates the involvement of phenolic oxygen atom towards coordination[24]. The IR data precludes the presence of a dimetallic structure, as in case of dimetallic structure the $v(\mathrm{C}-\mathrm{O})$ (phenolic) stretch is expected to shift[25] to higher energy by $>10 \mathrm{~cm}^{-1}$. The absence of $v(\mathrm{O}-\mathrm{H})$ in the coordination compounds indicates the deprotonation of the phenolic hydroxyl group. The above observation suggests the ONNO donor behaviour of the polystyrene supported Schiff bases.

Table 2. IR Spectral Data and Reflectance Spectral Data for Polystyrene-anchored Ligand and the Complexes

\begin{tabular}{|c|c|c|c|c|c|c|}
\hline $\begin{array}{l}\text { Polystyrene- } \\
\text { anchored } \\
\text { ligand/complexes }\end{array}$ & $v(C=N)$ & $\begin{array}{l}v(\mathrm{C}-\mathrm{O}) \\
\text { (phenolic) }\end{array}$ & $\begin{array}{l}v(C-O) \\
\text { (enolic) }\end{array}$ & $\begin{array}{l}v_{s y} \\
(O=M=O)\end{array}$ & $\begin{array}{l}V_{\text {asy }} \\
(O=M=O)\end{array}$ & $\begin{array}{l}v_{\max } \\
\left(\mathrm{cm}^{-1}\right)\end{array}$ \\
\hline $\mathrm{PSCH}_{2}-\mathrm{LH}_{2}$ & 1630 & 1530 & & & & \\
\hline $\mathrm{PSCH}_{2}-\mathrm{LNi}$ & 1610 & 1535 & 1230 & & & $\begin{array}{l}12550 \\
20100 \\
24800\end{array}$ \\
\hline $\mathrm{PSCH}_{2}-\mathrm{LMoO}_{2}$ & 1595 & 1540 & 1230 & 910 & 945 & \\
\hline $\mathrm{PSCH}_{2}-\mathrm{LUO}_{2}$ & 1605 & 1535 & 1220 & & 905 & \\
\hline
\end{tabular}

The polystyrene-anchored dioxo- uranium(VI) compounds exhibit a strong band at $905 \mathrm{~cm}^{-1}$ due to $v_{\text {asy }}(\mathrm{O}=\mathrm{U}=\mathrm{O})$ stretch, characteristic of the presence of the trans-UO $\mathrm{U}_{2}$ structure. The force constant $\left(\mathrm{f}_{\mathrm{U}-\mathrm{O}}\right)$ values[26] are 6.66-6.81 mdyn/ $\AA$ which are within the reported range(6.58-7.03 mdyn/ $\AA$ ) reported for the majority of the dioxouranium(VI) compounds[27]. The $\mathrm{U}-\mathrm{O}$ bond distance( $\mathrm{R}_{\mathrm{U}}$ o)[28] is $1.74 \AA$ and lies within the usual range(1.60-1.92 $\AA$ ) reported for the majority of dioxouranium(VI) compounds[29]. The dioxo- molybdenum(VI) compounds exhibit $v_{\mathrm{sy}}(\mathrm{O}=\mathrm{Mo}=\mathrm{O})$ and $v_{\mathrm{asy}}(\mathrm{O}=\mathrm{Mo}=\mathrm{O})$ stretches at $910 \mathrm{~cm}^{-1}$ and $945 \mathrm{~cm}^{-1}$ respectively. These bands are in the usual ranges 892-964 and 840$925 \mathrm{~cm}^{-1}$, respectively for the majority of $\mathrm{MoO}_{2}$ (VI) coordination compounds[30]. The IR data indicate the presence of cis- $\mathrm{MoO}_{2}$ structure as the compounds precludes the presence of an oligomeric structure[31] with $\cdots \mathrm{Mo}=\mathrm{O} \cdots \mathrm{Mo}=\mathrm{O} \cdots$ interaction. As the space between the adjacent metal centers 
in the polystyrene-anchored coordination compounds is occupied by the polymer backbone, the presence of such an oligomeric structure is precluded in our compounds.

The reflectance spectral data of the polystyrene-anchored coordination compounds are presented in Table 2. The polystyrene-anchored nickel(II) compounds exhibit two bands at $20100 \mathrm{~cm}^{-1}\left(v_{2}\right)$ and $24800 \mathrm{~cm}^{-1}\left(v_{3}\right)$ due to the ${ }^{1} \mathrm{~A}_{1 \mathrm{~g}}$ $\rightarrow{ }^{1} \mathrm{~A}_{2 \mathrm{~g}}$ and ${ }^{1} \mathrm{~A}_{1 \mathrm{~g}} \rightarrow{ }^{1} \mathrm{~B}_{1 \mathrm{~g}}$ transitions in a square planar geometry[32]. It also exhibit a weak band at $12550 \mathrm{~cm}^{-1}\left(v_{1}\right)$ which is assigned to a spin-forbidden ${ }^{1} \mathrm{~A}_{1 \mathrm{~g}}$ $\rightarrow{ }^{3} \mathrm{~A}_{2 \mathrm{~g}}$ transitions[32].

\section{REFERENCES}

[1] RD. Chatterjee, H.C. Bajai, A. Das and K. Shatt, Journal of Molecular Catalysis, 92,L235(1994), DOI:10.1016/0304-5102(94)00091-3.

[2] K.C. Gupta, and A.K. Sutar, Coordination Chemistry Reviews, 252, 1420(2008), DOI:10.1016/j.ccr.2007.09.005.

[3] M.R. Maurya, P. Saini, C. Haldar, A. K. Chandrakar and S. Chand, Journal of Coordination Chemistry, 65(16), 2903(2012), DOI:10.1080/00958972.2012.706281.

[4] D.C. Sherrington, Catalysis Today, 57, 87(2000), DOI:10.1016/S0920-5861(99)00311-9.

[5] A. Kumar, D. Kumar, P. K. Gupta, and D. Dass, Rasayan Journal of Chemistry, 12(2), 577(2019), DOI:10.31788/RJC.2019.1225081.

[6] T. Yokoyama, S. Asami, M. Kanesato and T. Suzuki, Chem. Lett., 2 (1993) 383.

[7] N. Das and J. Das, Indian J. Chem., 28A (1989) 150.

[8] D. Das, A. K. Das and C. Sinha, Talanta, 48 (1999) 1013.

[9] G. Marques, J. L. Bourdelande and M. Valiente, React. Funct. Polym., 41 (1999) 77.

[10] J. Fiestel, G. Popov and G. Schwachulla, Plast. Kautsh, 30 (1983) 496; M. A. Samsarzadeh and D. E. Hudgin, J. Polym. Sci., Part C, Polym. Lett., 24 (1986) 541.

[11] H. Kumagai, Y. Inoue, T. Yokoyama, T. M. Suzuki and T. Suzuki, Anal. Chem., 70 (1998) 4070 .

[12] A. Akelah, Masoud and S. S. Kandil, Indian J. Chem., 25A (1986) 918.

[13] D. Wohrle and H. Bohlon, Macromol. Chem., 187 (1989) 20.

[14] N. Nishizawa, T. Yokoyama, T. Kimura and T. M. Suzuki, Polyhedron, 5 (1986) 2047.

[15] A. Syamal and M. M. Singh, Indian J. Chem., 37A (1998) 350.

[16] H. Shirai, T. Takemoto and N. Hojo, Polym. Commun., 25 (1984) 284.

[17] Y. Nakajima, M. Fujiwara, T. Matshushite and L. T. Shono, Polyhedron, 5 (1986) 1601.

[18] T. Matshushita, J. Sakiyama. M. Fujiwara and T. Shono, Chem. Lett, (1988) 1577. 
[19] A. Syamal, M. M. Singh and D. Kumar React. Funct. Polym., 39 (1999) 27.

[20] D. Dolphin and A. Wick, “Tabulation of Infrared Spectral Data”, Wiley Interscience, New York, 1977, pp. 303, 304.

[21] A. Syamal and M. M. Singh, J. Polym. Mater., 6 (1989) 175.

[22] P. M. Parikh and J. R. Shah, Synth. React. Inorg. Met.-Org. Chem., 15 (1985) 769.

[23] K. Ueno and A. E. Mortell, J. Phys. Chem., 59 (1955) 998.

[24] A. Syamal and O. P. Singhal, Trans. Met. Chem., 4 (1979) 179.

[25] E. Sinn and C. M. Harris, Coord. Chem. Rev., 4 (1969) 998.

[26] S. P. McGlynn, J. K. Smith, W. C. Neely, J. Chem. Phys., 35 (1961) 105; C. T. Nguyen, G. M. Gegun and A. Palmer, Inorg. Chem., 31 (1992) 5280.

[27] A. Syamal and O. P. Singhal, Syn. React. Inorg. Met.-Org. Chem., 10 (1980) 243; G. L. Cadlow, A. B. V. Cleave and R. L. Eager, Can. J. Chem., 38 (1960) 772.

[28] L. H. Jones, Spectrochim, Acta, 10 (1958) 395; 11 (1959) 409.

[29] A. Syamal, Coord. Chem. Rev., 16 (1975) 309.

[30] A. Syamal and M. R. Maurya, Coord. Chem. Rev., 95 (1989) 183.

[31] E. I. Stiefel, Prog. Inorg. Chem., 22 (1971) 1.

[32] A. B. P. Lever, Inorganic electronic spectroscopy, Elsevier, Amsterdam, 2nd Edn, 1984. 